Article

\title{
Advanced NDT Methods and Data Processing on Industrial CFRP Components
}

\author{
Vito Dattoma, Francesco Willem Panella *, Alessandra Pirinu and Andrea Saponaro \\ Department of Innovation Engineering, University of Salento, 73100 Lecce, Italy; \\ vito.dattoma@unisalento.it (V.D.); alessandra.pirinu@unisalento.it (A.P.); andrea.saponaro@unisalento.it (A.S.) \\ * Correspondence: francesco.panella@unisalento.it; Tel.: +39-0832-297771
}

Received: 28 November 2018; Accepted: 14 January 2019; Published: 24 January 2019

check for updates

\begin{abstract}
In this work, enhanced thermal data processing is developed with experimental procedures, improving visualization algorithm for sub-surface defect detection on industrial composites. These materials are prone to successful infrared nondestructive investigation analyses, since defects are easily characterized by temperature response under thermal pulses with reliable results. Better defect characterization is achieved analyzing data with refined processing and experimental procedures, providing detailed contrasts maps where defects are better distinguished. Thermal data are analyzed for different CFRP specimens with artificial defects and experimental procedures are verified on real structural aeronautical component with internal anomalies due to impact simulation. A better computation method is found to be useful for simultaneous defect detection by means of automatic mapping of absolute contrast, optimized to identify defect boundaries.
\end{abstract}

Keywords: aeronautical component; CFRP; nondestructive testing; pulsed thermography; artificial defects; thermal contrast; ultrasonic method

\section{Introduction}

Internal defects are the major sources of composite failures in FRP structures and originate from manufacturing (delamination, voids, porosity, fiber wrinkles, etc.) and/or from in-service events (impact or fatigue damage, micro-cracks, debonding, delamination, erosion, etc.). A combination of contemporaneous voids, matrix cracks, and multiple delamination may occur, and structural integrity is verified using nondestructive testing (NDT) methods to determine the damage risk [1].

Thermal methods are most effective for thin laminates or for defects near the surface and the passive or active approach are adopted. In active IRT methods, an external stimulus is applied to specimen surface, in order to induce relevant thermal contrasts between regions of interest and these techniques include pulsed thermography (PT) as valid robust technique for checking the integrity of structures $[2,3]$ and consists of rapidly heating the specimen recording the temperature decay curve; the free-defect material conducts heat more efficiently than defective zones, where heat is either absorbed, or reflected, indicating the quality state of the inspected area [4].

Active IR-thermographic methods such as cooling down thermography (CDT) [5] or long pulsed thermography (LPT) [6,7] give satisfactory results for similar defects in composites. In this paper, PT thermography in the range of long pulses is explored, even that heat accumulation phenomenon may occur for subsurface defects. The CDT method represents an interesting and valid ND approach where a previous thermal excitation in an oven allows a uniform temperature through thickness and could be applied on CFRP plates, especially in the case of deeper defects.

However, this is not a suitable technique for wider structural component of the authors' lack of experience and need of a large climatic chamber. However, future CDT tests will be considered. 
Raw thermal imaging from PT investigation is usually not suitable for a precise material evaluation and a quantitative analysis of the registered temperatures is required to better determine the dimension, depth, and defect shape. Signal levels associated with subsurface anomalies can be lost in the thermal data noise [8] and proper different post-processing methods are used to improve the signal-to-noise (SNR) content of recorded data.

Several processing methods have been developed to improve delamination characterization for thermographic tools [9] and introduce automatic images analysis, actual main goal for thermographic inspection, providing a pass-or-fail diagnostic to the operator $[10,11]$. The literature on thermal image-processing proposes different algorithms developed to improve detect detection from thermal maps $[3,12]$ and, in the present paper, a different image-processing method is introduced, where defects are automatically visualized on thermal contrast maps for CFRP specimens and experimental procedure is optimized, in order to facilitate inspections for operators with automatic and accurate post-processing, at the same time with good reliability level to be guaranteed.

Since thermography is considered as an emerging technology, real component thermal contrast maps were verified using the well-established ultrasonic c-scanning technique, as explained in other works [13] for unknown damage area evaluation on composites, using modern phased array probe; several authors [14-16] make use of ultrasonic NDI systems for the reliable and effective detection of delaminations, the primary important damage mode for aeronautical applications, where fatigue and impact failures are likely to occur [17].

\section{Materials and Methods}

For the optimization and the calibration of thermal signal processing, standard specimens in the form of plates with artificial defects, built with expanded polystyrene inserts, are produced; these are crucial to determine the detectability limits of the proposed technique [18] for defect size, depth, and type certification after inspection.

\subsection{CFRP Plates and Component}

Thermographic study is here conducted on two composite plates made of CFRP material, denotated Plate- 1 and Plate-2. The specimens are based on aeronautical production plates, assembled to englobe artificial defects: two plates with different thicknesses were realized by bonding of two square laminates $(120.7 \times 120.7 \mathrm{~mm})$ with a central hole according to the constructive drawing shown in Figure 1a. The plates of different thickness are glued together; polystyrene defects are made from original aeronautical plates and inserted in between layers, to simulate inclusions and delaminations, and two inserts are glued together to create a double defect thickness. The different sizes of defects enable the study the influence of their size, depth (different if measured from the opposite sides), and eventually thickness for a reliable detection [18].

The original laminates are based on symmetric lamina oriented $\pm 0 / 90^{\circ}$, coupled with $\pm 45^{\circ}$ at surface sides and the polymeric inserts in the form of disks were glued individually or in pairs to create a defect different thickness of $0.6 \mathrm{~mm}$ and $1.2 \mathrm{~mm}$, respectively. In Plate I, the thickness of the laminates for Side A is $4.9 \mathrm{~mm}$ (for 14 layers) and $2.8 \mathrm{~mm}$ (Side B with 8 layers), for a total of $7.7 \mathrm{~mm}$ (Figure 1b). In Plate II, the thicknesses are respectively $2.1 \mathrm{~mm}$ (Side A of 6 layers) and $2.8 \mathrm{~mm}$ (Side B of 8 layers) for a total of $4.9 \mathrm{~mm}$.

Plate I allows to analyses defects of elevate depth and defects with different sizes as in Figure 1a and in Table 1 to study the relationship between different defects, according to size and depth together. The aim of lower specimen thickness is to analyze artificial defects of the same nature but with smaller diameter. Only the side-A of Plate II is covered with non-shiny black paint to eliminate reflection problems, because the $5 \mathrm{~mm}$ diameter defects are carefully inspected on that side of specimen. The information in terms of thermal conductivity and density of the CFRP constituents are shown in Table 2. 
Table 1. Artificial defect geometry in the plates.

\begin{tabular}{cccccccc}
\hline Defect Nomenclature & D1 & D2 & D3 & D4 & D5 & D6 & D7 \\
\hline N. Defect in Plate I & 1 & 2 & 1 & 3 & 2 & 1 & 3 \\
\hline N. Defect in Plate II & 1 & 2 & 1 & 3 & 2 & 1 & 3 \\
\hline Diameter $(\mathbf{m m})$ & 25 & 10 & 15 & 5 & 10 & 15 & 5 \\
\hline Thickness $(\mathbf{m m})$ & 0.6 & 0.6 & 0.6 & 0.6 & 1.2 & 1.2 & 1.2 \\
\hline
\end{tabular}

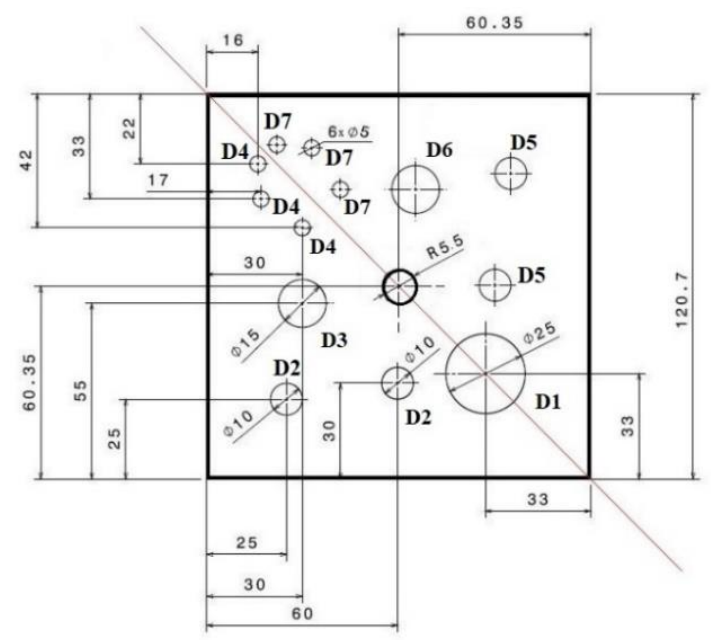

(a)

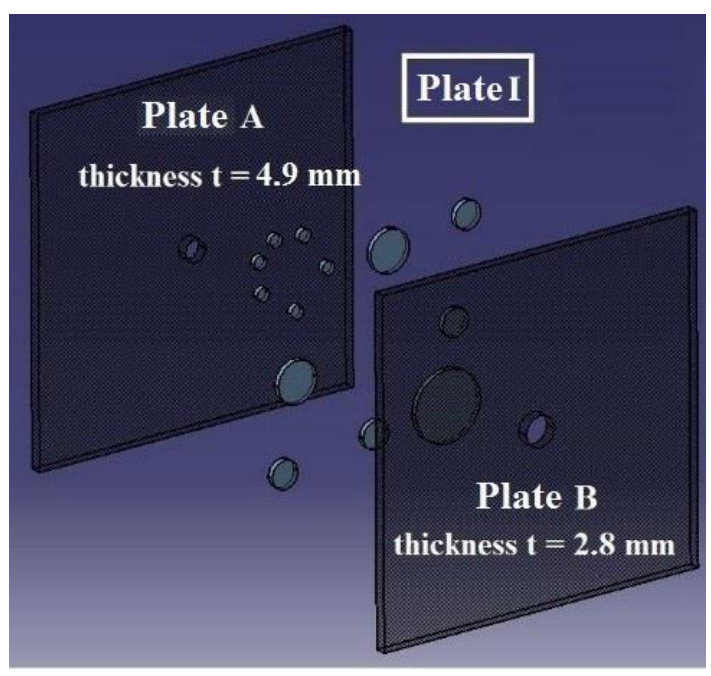

(b)

Figure 1. (a) Layout of artificial defects and position. (b) Exploded Assembly of Plate I, identical for Plate II.

Table 2. Mechanical properties of carbon fiber and epoxy resin.

\begin{tabular}{|c|c|}
\hline \multicolumn{2}{|c|}{ Carbon Fiber } \\
\hline Density $\left(\mathrm{g} / \mathrm{cm}^{3}\right)$ & 1.65 \\
\hline Areal weight $\left(\mathrm{g} / \mathrm{m}^{2}\right)$ & 240 \\
\hline Thermal conductivity coefficient $(\mathrm{W} / \mathrm{mK})$ & $\sim 15$ \\
\hline \multicolumn{2}{|c|}{ Epoxy Resin } \\
\hline Density $(\mathrm{g} / \mathrm{ml})$ & $1.14-1.16$ \\
\hline Young Modulus (MPa) & $2900-3100$ \\
\hline Ultimate stress (MPa) & 75-80 \\
\hline Ultimate strain $(\%)$ & $8.5-9$ \\
\hline Thermal conductivity coefficient (W/mK) & $\sim 0.22$ \\
\hline
\end{tabular}

In addition, an aeronautical multi-stringer component of medium size (Dim. $914.4 \times 762 \mathrm{~mm}$ ) in carbon fiber is studied; Figure 2a shows the geometry of the structural component; CFRP laminates are based on different ply layers (Table 3). In this component, rivets secure the ribs on the skin, while stringers are co-cured. 


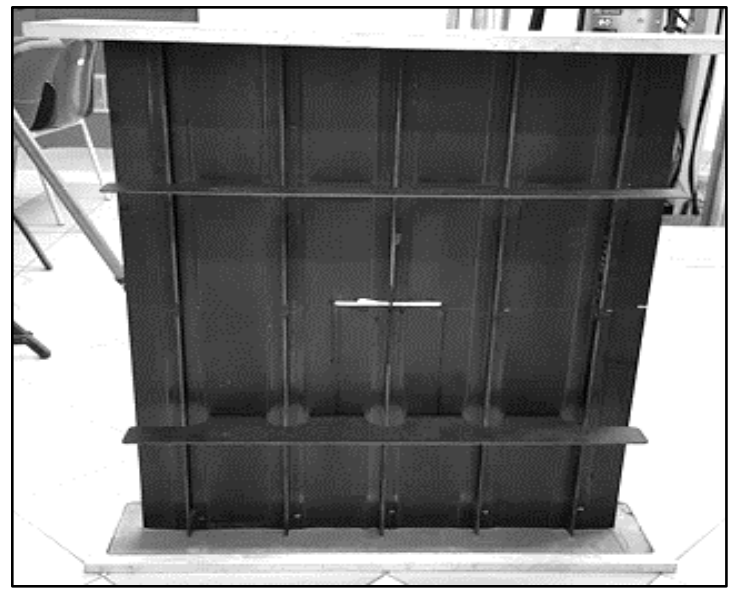

(a)

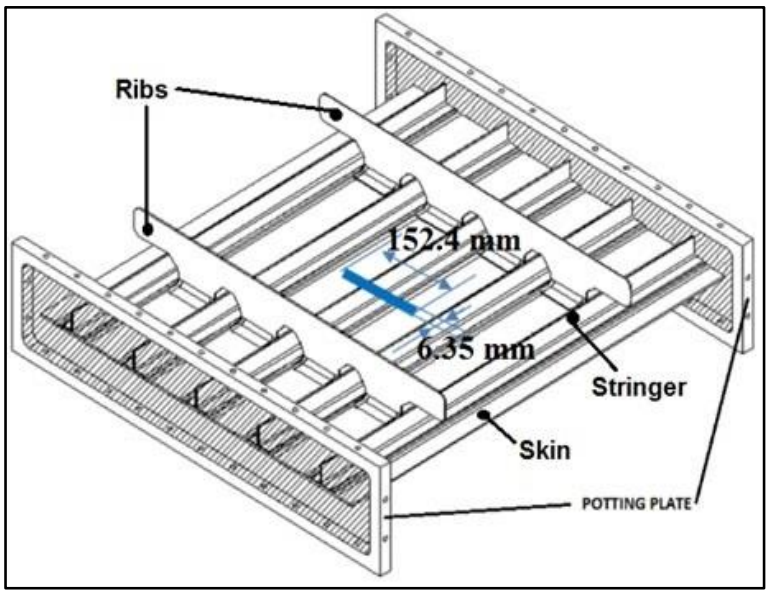

(b)

Figure 2. (a) CFRP multi stringer multi-stringer component's geometry and (b) and artificial damage geometry.

Table 3. Part components for multi-stringer element.

\begin{tabular}{cccccc}
\hline $\begin{array}{c}\text { Part } \\
\text { Component }\end{array}$ & $\begin{array}{c}\text { Sub-Part } \\
\text { Component }\end{array}$ & Material & $\begin{array}{c}\text { Lamina } \\
\text { Thickness (mm) }\end{array}$ & $\begin{array}{c}\mathbf{N}^{\circ} \\
\text { Plies }\end{array}$ & Stacking Sequence \\
\hline Skin & Skin 1 & CFRP & 0.186 & 20 & {$[45 / 90 /-45 /-45 / 45 / 90 / 0 /-45 / 45 / 0]_{\mathrm{S}}$} \\
& Skin 2 & CFRP & 0.186 & 24 & {$[45 / 90 / 0 / 0 /-45 /-45 / 45 / 90 / 0 /-45 / 45 / 0]_{\mathrm{S}}$} \\
\hline Stringer & & CFRP & 0.186 & 12 & {$[45 / 90 / 0 / 0 /-45 / 0]_{\mathrm{S}}$} \\
\hline Rib & & CFRP & 0.208 & 12 & {$[45 / 0 /-45 / 90 / 45 / 0]_{\mathrm{S}}$} \\
\hline
\end{tabular}

The component presents an artificial discontinuity in the center, in the form of a large cut (Dim. $152.4 \times 6.35 \mathrm{~mm}$ ) to simulate the effect of heavy impact, leading to central stiffener collapse; this artificial damage on the central skin interrupts the stringer continuity and simulates the presence of severe damage in whole area (Figure $2 b$ ), which is expected to produce delaminations during static testing before failure. The information in terms of material and lamina property constituents are shown in Table 3.

\subsection{Experimental Setup and Inspection Methods}

Pulsed thermographic tests have been conducted with long pulses in the experimental laboratory located in the Engineering Faculty of the University of Salento (Lecce, Italy). Thermographic set-up means both the equipment used to test and the appropriate arrangement of specimen position and excitation are influent on results [19].

The equipment consists of an array of four halogen lamps, each of $1000 \mathrm{~W}$, controlled by a signal generator with single square wave form of amplitude set to maximum lamp power and period calculated on the base of established heating time in following tables to synchronize thermal pulse and recording acquisition; a FLIR 7500M IR camera (FLIR Systems, Inc., Wilsonville, OR, U.S.), with a FPA cooled detector, endowed with NETD $25 \mathrm{mK}$ In-Sb sensor and image resolution of $320 \times 256$ pixels; a custom processing software. Previously cited experimental campaigns defined optimal set-up possibilities for a better characterization of defects on similar CFRP plates [18,20], suitable thermographic parameters in terms of heating times in the range 12-40 s (capable to better identify defect depths in 2-6 mm range with low power halogen lamps thermal input), experimental configuration distance, frame rate acquisition, and lamp configuration.

For NDT, the specimen's surface is positioned at $0.5 \mathrm{~m}$ from lamps and an expanded polystyrene support is applied because of thermal insulation avoids board effects, performing acquisitions based on previous experimental experience [18]; Figure 3 shows the optimal setup of the thermographic 
apparatus used for all tests, to ensure acceptable uniform heating of the exposed surface, 12 total tests are conducted: 6 on Plate I (three for both sides) and 6 on Plate II (three for both sides), selecting different heating times (Table 4 ).

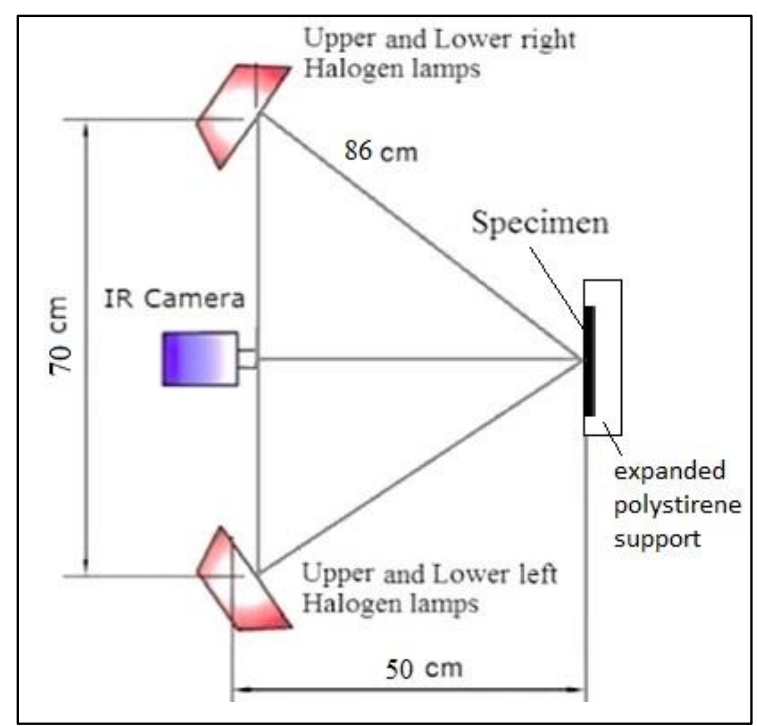

(a)

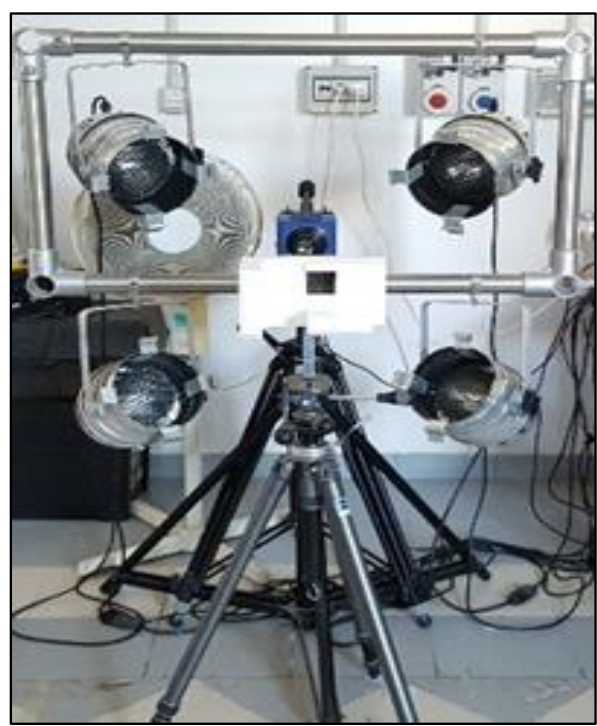

(b)

Figure 3. (a) Top view of the thermographic setup for CFRP plates' acquisition and (b) experimental setup.

Table 4. Scheduling tests for the investigations with different heat pulses.

\begin{tabular}{|c|c|c|c|c|c|c|}
\hline $\begin{array}{c}\text { CFRP } \\
\text { Specimen }\end{array}$ & Side & $\mathbf{N}^{\circ}$ Test & $\begin{array}{c}\text { Frame Rate } \\
(\mathrm{Hz})\end{array}$ & $\begin{array}{l}\text { Heating } \\
\text { Time (s) }\end{array}$ & $\begin{array}{l}\text { Acquisition } \\
\text { Time (s) }\end{array}$ & $\begin{array}{c}\text { Total } \\
\text { Frames }\end{array}$ \\
\hline \multirow{6}{*}{ Plate I } & \multirow{3}{*}{$\mathrm{A}$} & 1 & 5 & 20 & 100 & 500 \\
\hline & & 2 & 5 & 30 & 100 & 500 \\
\hline & & 3 & 5 & 40 & 100 & 500 \\
\hline & \multirow{3}{*}{ B } & 4 & 5 & 12 & 200 & 1000 \\
\hline & & 5 & 5 & 15 & 200 & 1000 \\
\hline & & 6 & 5 & 20 & 250 & 1250 \\
\hline \multirow{3}{*}{ Plate II } & \multirow{3}{*}{ A, B } & 7,8 & 5 & 12 & 200 & 1000 \\
\hline & & 9,10 & 5 & 15 & 200 & 1000 \\
\hline & & 11,12 & 5 & 20 & 250 & 1250 \\
\hline
\end{tabular}

For the multi-stringer component, preliminary ultrasonic inspections are conducted with phased array technology, which generally provides the pulses controlled excitation (e.g., amplitude and delay) of single elements in a multi-element probe, as opposed to single-element probes for conventional UT [21]. The excitation of piezo-composite elements can generate a focused ultrasonic beam with the possibility to modify parameters such as beam and angle, focal distance through software. The phased array system uses the physical principle of multiple progressive sound waves, varying the time between a series of ultrasonic pulses [22]. The wave front generated by combination of element array pulses at slightly different times allows pulses to direct and distribute the sonic beam and achieve a sharp focus of perfectly distributed beam characteristics [18].

UT phased array (PA) control is conducted using a portable modular unit Olympus OmniScan MXU(Olympus Corporation, Shinjuku, Tokyo, Japan) instrument with an innovative technological 64 elements phased array 2.25L64-A2 probe of thickness $25 \mathrm{~mm}$ with $2.25 \mathrm{MHz}$, a SA2-0L plexiglas longitudinal wedge, with glycerin coupling gel and the Olympus mini-wheel absolute encoder with a resolution of 12 steps/mm for C-scan control mode (as shown in Figure 4a). 


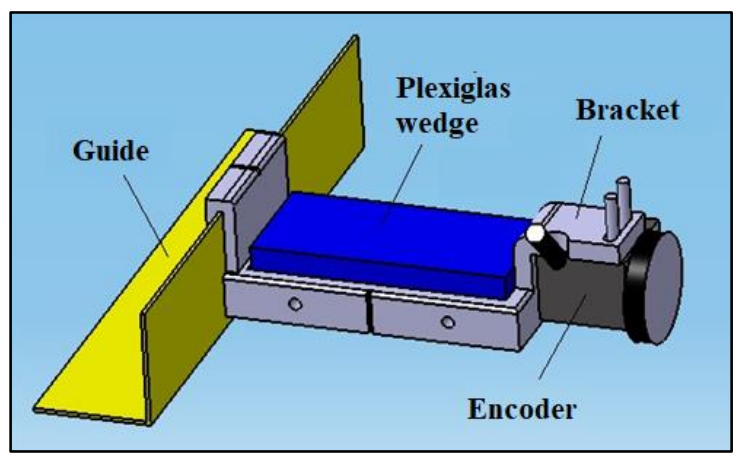

(a)

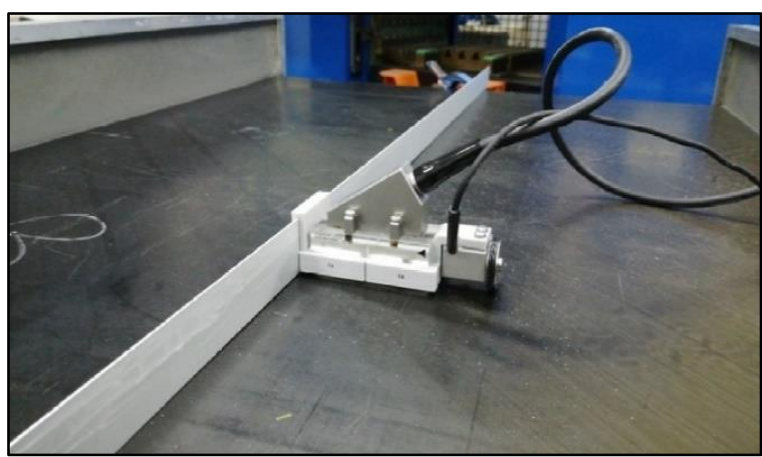

(b)

Figure 4. (a) CATIA assembly view of new PLA bracket tool and (b) experimental setup for ultrasonic C-scan controls around simulated impact zone of aeronautical component.

The authors used the UT C-scan technique to provide a two-dimensional representation of defects in a specific parallel plane below inspected surface and scans of ultrasonic data are synchronized with the unidirectional movement of the probe itself, along the main scan line and this is possible by rigidly coupling an encoder to the ultrasonic probe, moving along a sliding guide.

In previous works, appropriate UT tools are designed to allow stable coupling to GFRP components [23] with ultrasonic inspections. In our case, ultrasonic probe must be maintained in a steady orientation and contact conditions relative to inspected component [23] and for this goal, a special bracket is conceived with specific geometric dimensions for Plexiglas wedge (as seen in Figure 4a), constructed in thermoplastic polymeric material PLA with Ultimaker2 3D printer. Figure 4b show experimental setup employed on CFRP component in direct contact with aid of coupling gel, since water stream method would give similar results.

Thermal pulsed acquisitions of multi-stringer part are successively performed and focused on central impacted damage area to verify defect data correlation with UT controls.

Aeronautical component surface is positioned at a higher distance of $0.72 \mathrm{~m}$ from the four halogen lamps than CFRP plates, due to necessary of inspection on a larger delamination zone around the impact simulated cut with a fixed focal point of the camera. Figure 5 shows the thermographic setup that is used for all tests described in the case of computed inspection.

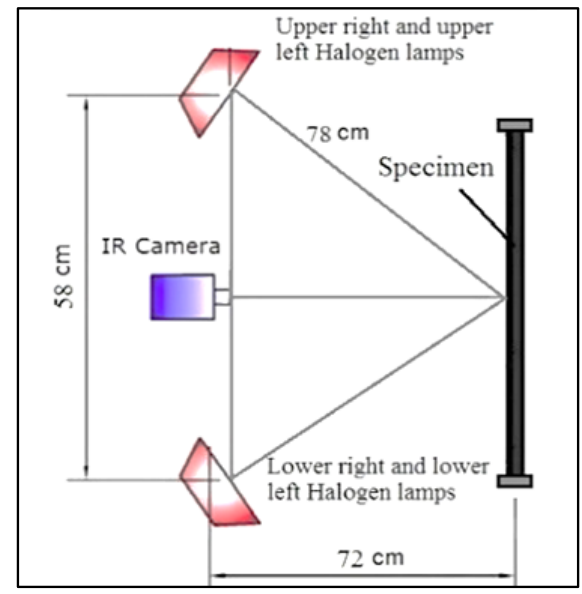

(a)

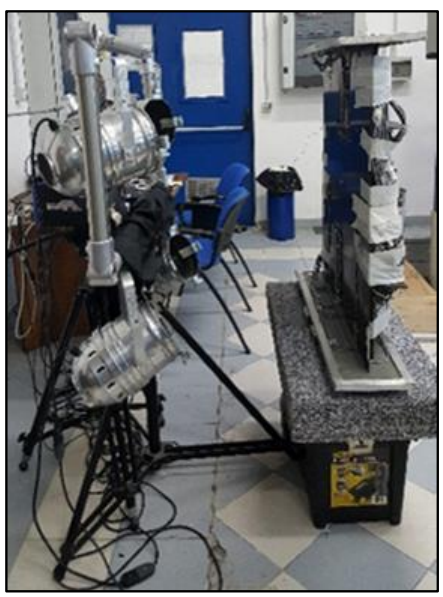

(b)

Figure 5. (a) Lateral view of the thermographic setup for multi-stringer component's acquisition and (b) experimental setup.

Employing this set-up, pulsed thermography is executed on CFRP component, in the central zone; five total tests are conducted, by selecting different heating times (Table 5). 
Table 5. Scheduling tests for the multi-stringer component's investigation.

\begin{tabular}{ccccc}
\hline $\mathbf{N}^{\circ}$ Test & Frame Rate $[\mathrm{Hz}]$ & Heating Time [s] & Acquisition Time [s] & Total Frames \\
\hline 1 & 5 & 20 & 100 & 500 \\
2 & 5 & 30 & 100 & 500 \\
3 & 5 & 40 & 100 & 500 \\
4 & 5 & 12 & 200 & 1000 \\
5 & 5 & 15 & 200 & 1000 \\
\hline
\end{tabular}

All tests are performed in controlled ambient temperature between $21-25^{\circ} \mathrm{C}$ for thermal analysis on CFRP elements, monitored by humidity/temperature data logger PCE-HT110, without input in the camera software.

\section{Data Processing and Image Elaboration Procedures}

The thermal contrast is the chosen parameter for defect localization by means of pulsed thermography; the surface temperature contrast is used to better investigate defect detectability and offers a qualitative comparison between standard defect and real delamination. Automatic advanced image-processing with preliminary algorithm is implemented in the MATLAB R2014b (The MathWorks, Inc., Natick, MA, USA, 2014) environment, to upload the three-dimensional matrix of thermal frames and to return selected thermal maps of specimen for various tests; local contrast is determined, highlighting various heat accumulation sites obtained over time, intact zones, and damaged areas [20] processed together with the absolute contrast parameter $C_{A}$, defined by the equation

$$
C_{A}(t)=T_{D Z}-T_{I Z}
$$

where the two terms $T_{D Z}$ and $T_{I Z}$ are the mean temperature in defect and intact zones during the cooling phase. Contrast analysis has limitation due to the used set-up and the operator's choice of reference intact areas for the contrast computation, for which following applied examples show some variability of results and correct definition of suitable intact reference zone for each selected defect is time consuming, especially if implemented in automated analysis.

The authors suggest developing an algorithm with different approach, to possibly improve defect and visibility defect shape on the base of absolute contrast approach. Preliminary study is conducted to investigate defect by raw temperatures analysis in a chosen thermal frame; defect characterization and automated contrast mapping with accurate methodology represent the main purpose of paper.

In this work, temperature perturbations as function of variable time is not considered for simplicity and a contrast enhance algorithm is proposed to map his values, as distributed completely on whole inspected specimen. This enhanced thermal contrast algorithm automates the simultaneous detection and mapping of contrast as optimized to identify defect boundaries according only to spatial variations in neighboring of each $[i, j]^{\text {th }}$ calculation point in the whole frame; in other words, the local contrast is automatically determined by calculating in the surroundings of a highest temperature spot in pre-defined areas the temperature variation $\Delta T$. For a general location $[i, j]$ on the thermal image, the new contrast parameter $C$ is defined through the formula

$$
C_{(i, j)}=\Delta T_{(i, j)}=\left|\overline{T_{D_{(i, j)}}}-\overline{T_{I Z_{(i, j)}}}\right|
$$

where, for each pixel of the thermographic image, the implemented MATLAB algorithm reworks the differences of the two mean temperatures $T_{D(i, j)}$ of the presumed defect in $[i, j]^{\text {th }}$ calculation point and $T_{I Z(i, j)}$ temperature, calculated as mean value in a reference rectangular zone around $[i, j]^{\text {th }}$ calculation point. The new algorithm is based on basic principle that reference temperatures evaluated around the inspected spot tends to maximize different values when trepassing the defect border, leading to local contrast variations to be displayed, clearly distinguishing defect shape and boundaries. 
The algorithm processes temperatures in iterative manner over the whole thermal map, without choosing an intact reference zone. This elaboration was inspired by DIC technique, where the correlation between the pixels does not occur in a temporal way, but punctual way, highlighting the maximum contrast reached in the proximity of defect border.

\subsection{Reference Absolute Contrast}

Even when undamaged zone definition is straightforward, considerable variations of results are observed with different location choice of reference zone and with different dimension of the identified damaged area.

The source distribution image (SDI) was developed for selecting free-defects portions of specimen that receives the same thermal flow of the corresponding inspected spot [24].

In Figures $6 \mathrm{a}$ and $7 \mathrm{a}$, examples of thermal map analysis at the beginning of the cooling phase allows to estimate the heat distribution quality, as well as the presence of heat pre-accumulation in real component and in the artificial plate. Although heat distribution appears not to be uniform due to wide component dimensions, we observed the cooling phase to produce more uniform temperature maps over time and local temperature gradients remaining only in the defected regions.

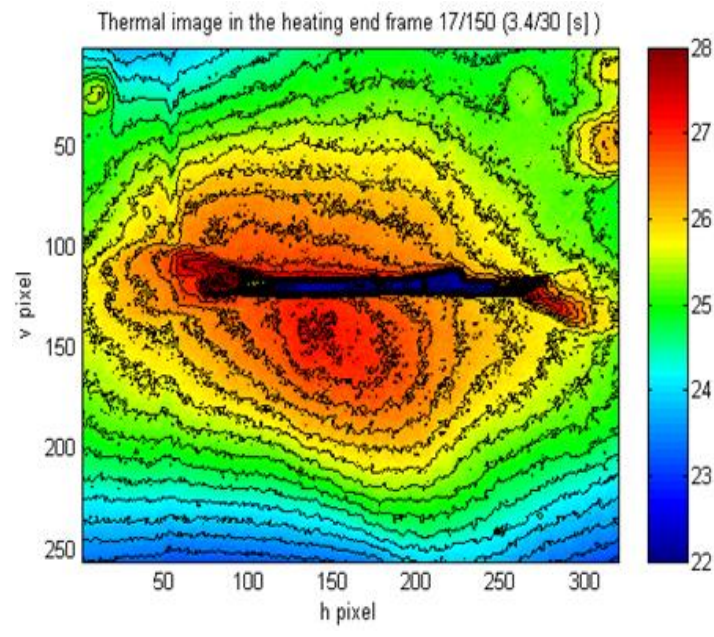

(a)

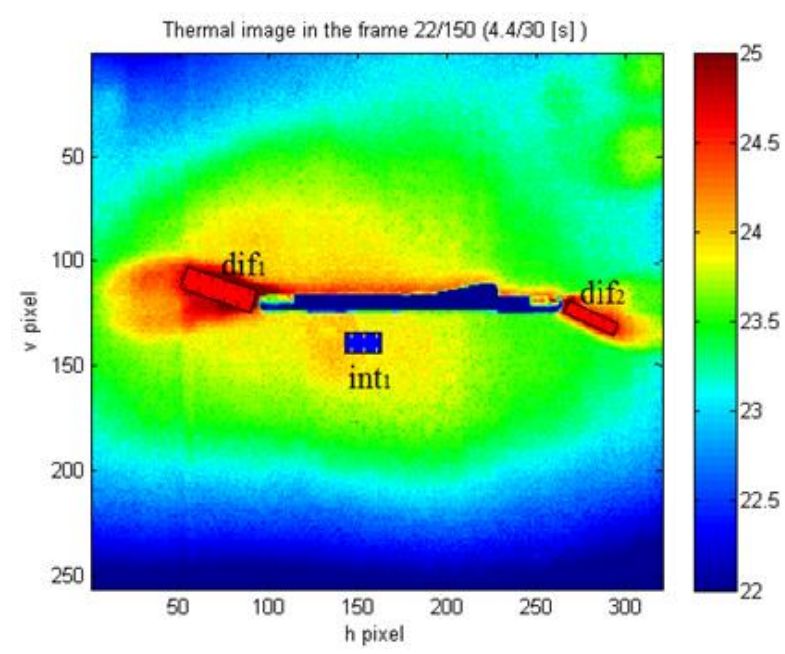

(b)

Figure 6. (a) Map of isotherm at the beginning of the cooling phase for real component and (b) raw thermal image for the central damaged zone of real component using heating time of $7 \mathrm{~s}$.

The preliminary algorithm considers the selection of the reference intact spots, corresponding to the previously determined defective regions as indicated in Figure 8a. On the bases of equal excitation energy, absolute contrast evaluation is enhanced with reduced errors.

After choosing a thermal frame where the defects are more distinguishable, the algorithm provides an interactive analysis procedure for selected defective and intact zones section. This procedure is automatically iterated many times for all defects; Figure $7 \mathrm{~b}$ shows an example on Plate I for processing a $25 \mathrm{~mm}$ diameter defect (dif1), a $10 \mathrm{~mm}$ diameter defect (dif2) and reference intact zone (int1). In the same way, on the central zone of the multi-stringer component, Figure $6 \mathrm{~b}$ highlights the left (dif1) and right (dif2) damaged areas beside the central cut and the reference intact area (int1) as an example for calculation, since the component has been previously loaded under compression and failure is accumulated around the artificial discontinuity.

From temperatures acquired in the selected spots, the MATLAB routine elaborates the absolute contrasts, as calculated in the selected zones. The code provides diagrams of $C_{A}$ during time, for a more reliable comparison between different damaged zones. Figures $8-11$ show examples of typical 
thermal profiles of intact zones and defective areas and the relative Absolute contrast behavior; in both cases, $C_{A}$ gives values from $0.9^{\circ} \mathrm{C}$ up to $4^{\circ} \mathrm{C}$, indicating the defect intensity.

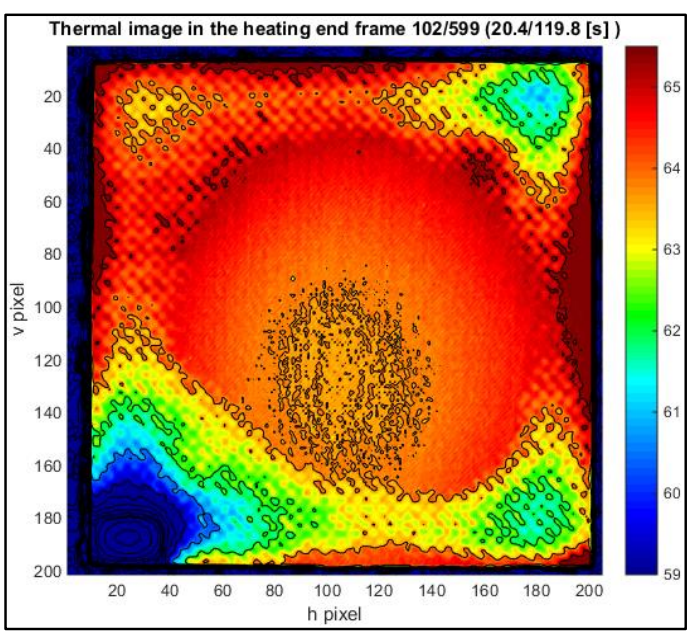

(a)

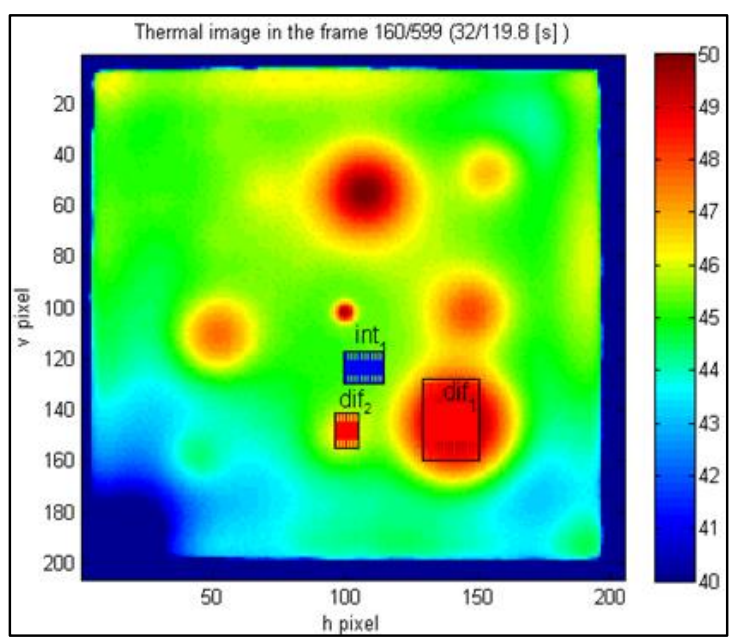

(b)

Figure 7. (a) Map of isotherms at the beginning of the cooling phase for artificial Plate I and (b) defect presence example on raw thermal image, using heating time of $20 \mathrm{~s}$.

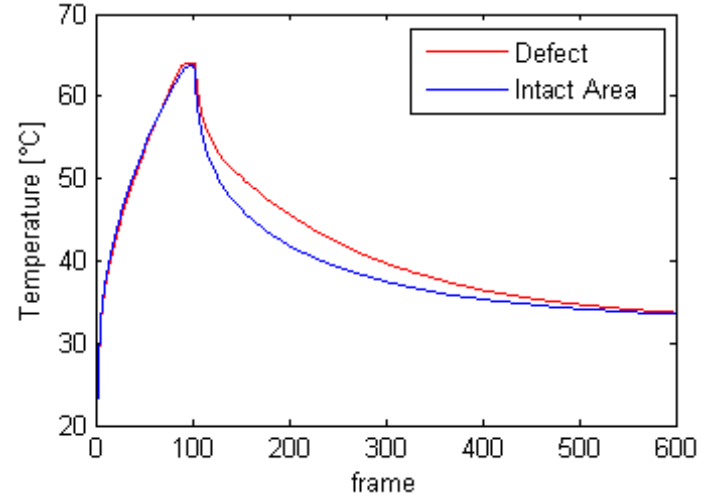

(a)

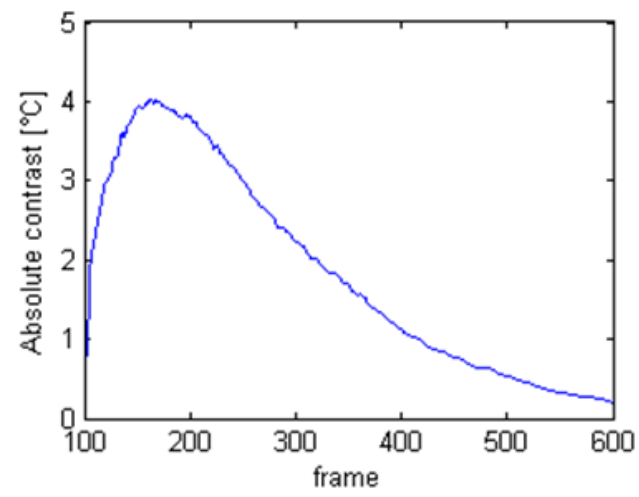

(b)

Figure 8. (a) Thermal profiles and (b) absolute contrast example for defect-1 (Ø $25 \mathrm{~mm})$ and intact area in Plate I, using heating time of $20 \mathrm{~s}$.

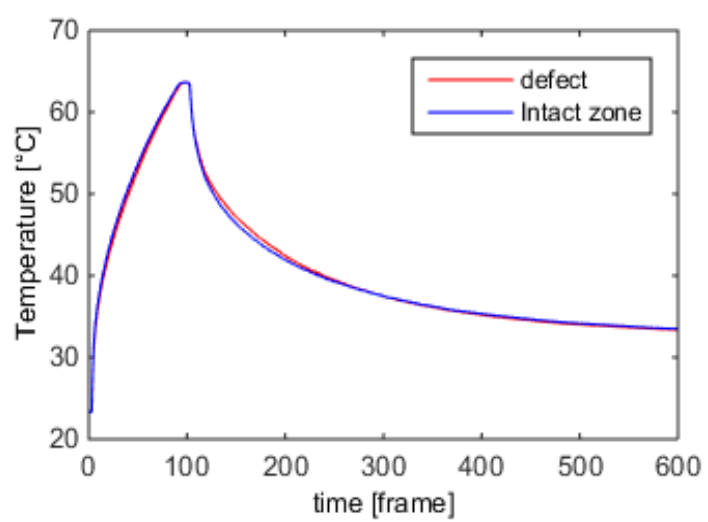

(a)

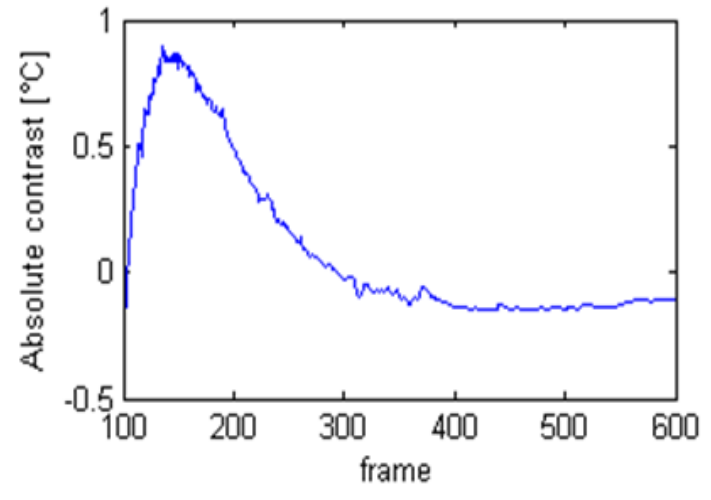

(b)

Figure 9. (a) Thermal profiles and (b) absolute contrast example for defect-2 (Ø $10 \mathrm{~mm})$ and intact area in Plate I, using heating time of $20 \mathrm{~s}$. 


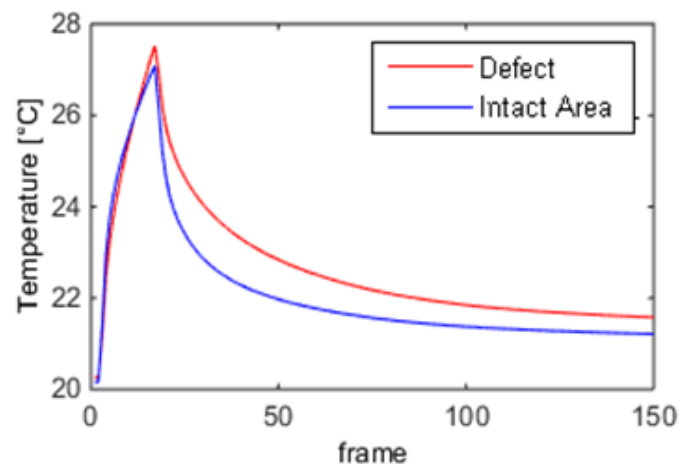

(a)

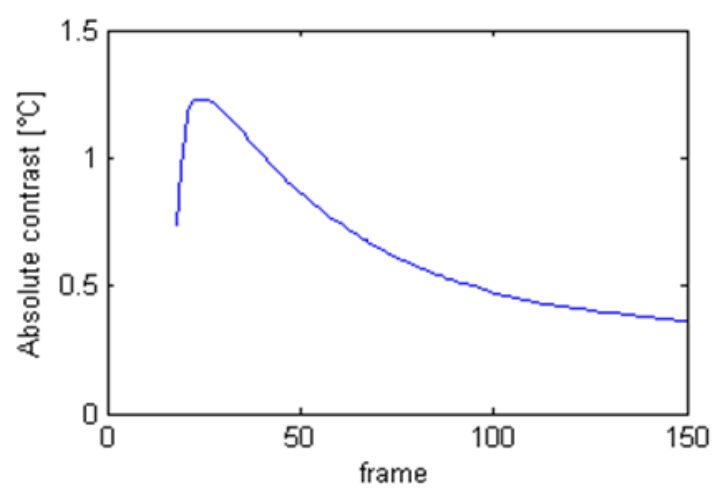

(b)

Figure 10. (a) Thermal profiles on multi-stringer component on left side of impact and (b) absolute contrast curve for delaminations with respect to intact area, using heating time of $7 \mathrm{~s}$.

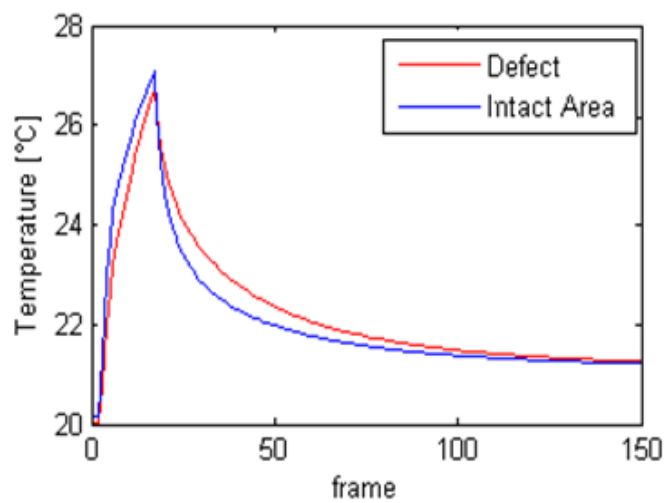

(a)

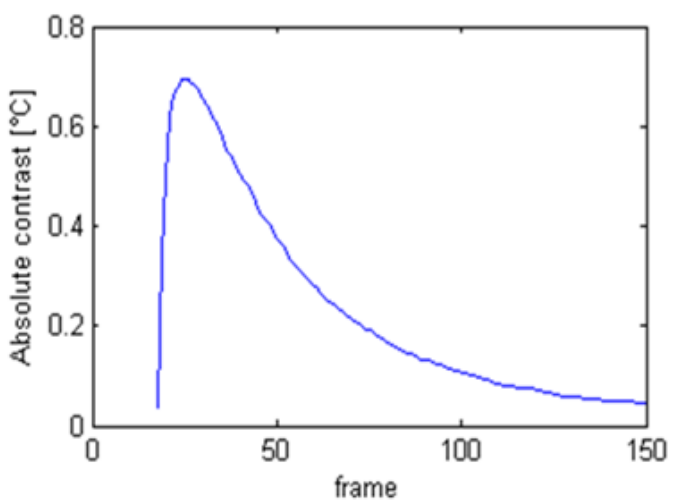

(b)

Figure 11. (a) Thermal profiles on multi-stringer component on right side of impact and (b) absolute contrast curve for delaminations with respect to intact area, using heating time of $7 \mathrm{~s}$.

The following Tables 6 and 7 report the detected maximum values of absolute contrast $\left(C_{A \_M A X}\right)$, as evaluated for two example defects in different computation zones, displayed in Figure $7 \mathrm{~b}$. The first table shows results for rectangular shape computation zone for defective zones of $20 \times 30$ pixel and of $10 \times 15$ pixel for same Defect 1 and zones of $8 \times 14$ pixel and of $5 \times 10$ pixel for same Defect 2 . The general result is a significant contrast variation for the same defect as function of selected computational zones extension.

Table 6. Maximum absolute contrast value for rectangular computation shape zone.

\begin{tabular}{cccccc}
\hline & \multicolumn{2}{c}{$C_{A_{-} M A X}$ of Defect $\mathbf{1}\left({ }^{\circ} \mathbf{C}\right)$} & \multicolumn{2}{c}{$C_{A_{-} \text {MAX }}$ of Defect 2 $\left({ }^{\circ} \mathbf{C}\right)$} \\
\hline & Intact Zones $\left(\mathbf{p x}^{\mathbf{2}}\right)$ & Area $\mathbf{2 0} \times \mathbf{3 0}$ & Area $\mathbf{1 0} \times \mathbf{1 5}$ & Area $\mathbf{8} \times \mathbf{1 4}$ & Area $\mathbf{5} \times \mathbf{1 0}$ \\
\hline & $\mathbf{1 4} \times \mathbf{1 2}$ & 4.02 & 4.72 & 0.9 & 0.99 \\
& $\mathbf{2 1} \times \mathbf{3 0}$ & 4.87 & 5.57 & 1.74 & 1.83 \\
& $\mathbf{1 4} \times \mathbf{2 0}$ & 3.73 & 4.43 & 0.62 & 0.72 \\
& $\mathbf{1 9} \times \mathbf{2 0}$ & 3.41 & 4.11 & 0.37 & 0.46 \\
Mean Value & $\mathbf{1 3} \times \mathbf{2 0}$ & 3.84 & 4.55 & 0.75 & 0.84 \\
\hline Standard Deviation & & 3.97 & 4.68 & 0.87 & 2.00 \\
\hline
\end{tabular}


Table 7. Maximum absolute contrast value for rectangular and circular computation shape zone.

\begin{tabular}{cccccc}
\hline \multicolumn{7}{c}{$C_{A_{-} M A X}\left({ }^{\circ} \mathbf{C}\right)$} \\
\hline \multicolumn{5}{c}{ Rectangular Area $\left(\mathbf{p x} \mathbf{x}^{*} \mathbf{p x}\right)$} & \multicolumn{4}{c}{ Circular Area (Ø px) } \\
\hline \multirow{2}{*}{ Intact Zone Size } & Def. $\mathbf{1}$ & Def. $\mathbf{2}$ & Intact Zone & Def. 1 & Def. $\mathbf{2}$ \\
& $\mathbf{2 0} \times \mathbf{3 0}$ & $\mathbf{8} \times \mathbf{1 4}$ & Size & $\boldsymbol{\varnothing ~ 3 3}$ & $\boldsymbol{\varnothing ~ \mathbf { 9 }}$ \\
\hline $\mathbf{1 4} \times \mathbf{1 2}$ & 4.02 & 0.9 & $\mathbf{1 4}$ & 1.27 & 1.81 \\
$\mathbf{2 1} \times \mathbf{3 0}$ & 4.87 & 1.74 & $\mathbf{3 0}$ & 0.91 & 1.49 \\
$\mathbf{1 4} \times \mathbf{2 0}$ & 3.73 & 0.62 & $\mathbf{2 0}$ & 1.11 & 1.68 \\
$\mathbf{1 9} \times \mathbf{2 0}$ & 3.41 & 0.37 & $\mathbf{1 6}$ & 2.38 & 2.90 \\
$\mathbf{1 3} \times \mathbf{2 0}$ & 3.84 & 0.75 & $\mathbf{1 8}$ & 1.69 & 2.12 \\
\hline Mean Value & 3.97 & 0.87 & & 1.47 & 2.00 \\
Standard Deviation & 0.55 & 0.52 & & 0.58 & 0.55 \\
\hline
\end{tabular}

The second Table compares results for rectangular and circular shape zones (diameter $\varnothing 33$ pixel for Defect 1 and diameter $\varnothing 9$ pixel for Defect 2), as seen in Figure 12, showing higher contrast values in the case of rectangular shape with respect to circular shapes for defect 1 in any zone size and higher contrast values in the case of circular shape zones for Defect 2. These Tables illustrate the variation contrast results with the operator choice of both shapes and size for reference and damaged areas.

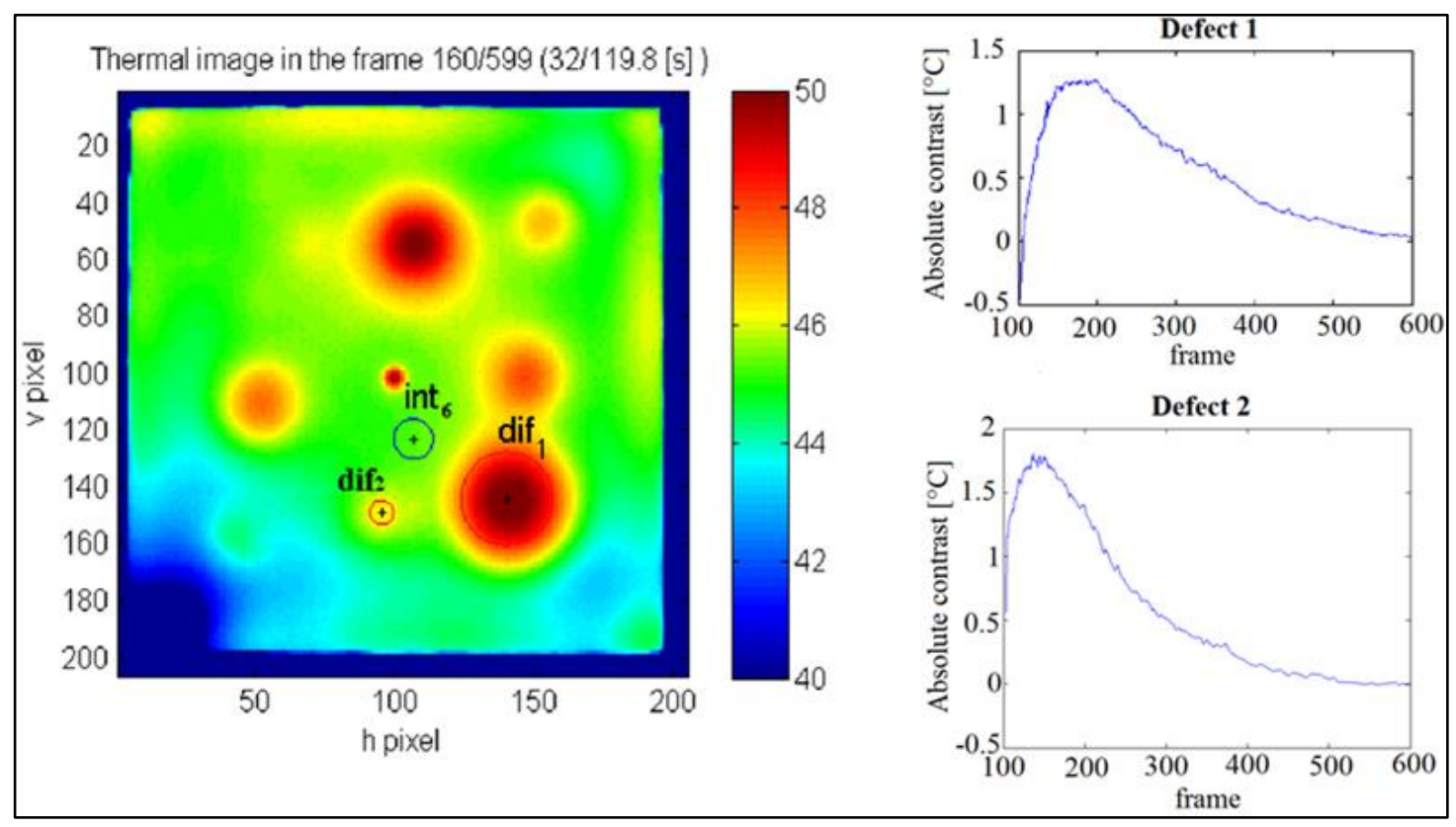

Figure 12. Raw thermal image of Plate I with circular reference zones and defect's relative Absolute contrast examples.

In the Tables, we can notice the intact zone's choice significantly influences the analytical determination of the thermal contrast curve, used to characterize the defect intensity. From the previous images, sometimes heat is not uniform on the specimen surface and the choice of intact areas is a determining factor in the contrast computation.

Simple circular shape is chosen because optimal for artificial circular defects, instead rectangular shape is considered firstly because very different with respect to circular shape and capable to detect delaminations in structural squared real elements. 


\subsection{Custom Mapping Optimization in Terms of Thermal Contrast Measurements}

The determination of the thermal contrast has the limitation to be performed at the local level and undergoes preliminary costly choices of specific thermal frames and zones to be investigated. When the heat quantity deposited by the external source is not uniform and the computation zones have slightly different cooling temperatures and gradients, some defects can be misjudged as identical. In any case, is necessary to analyze a single defect at a time: therefore, it was necessary a new method to be implemented on MATLAB and take in account such limitation and improve the processing technique to enhance the inspection defects in terms of accuracy and reduced time.

The new contrast algorithm allows direct defect mapping on the case of the value of contrasts, as distributed on inspected specimen. In this way, the method automates the determination and mapping simultaneously of the local contrast, to identify defect boundaries onto the analyzed component. In other words, the local contrast is automatically determined, investigating every zone with highest temperature in pre-defined areas.

For each pixel of the thermographic image, new MATLAB procedures rework the variation of temperatures determined in a two-dimensional array of pixels in the proximity of the calculation point. This algorithm is based on the principle for which temperatures computed around the chosen inspected spot tend to reach similar values when location corresponds to defect border, leading to contrast values being displayed with zero values on contrast maps, clearly distinguishing the damaged zones and defect shape. Figure 13 shows a comparison between original thermal map (Figure 13a) and the proposed contrast image (Figure 13b) of CFRP Plate I on Side B (defects' depth of $2.8 \mathrm{~mm}$ ) obtained after 11.6 cooling seconds after heating pulse of $20 \mathrm{~s}$.

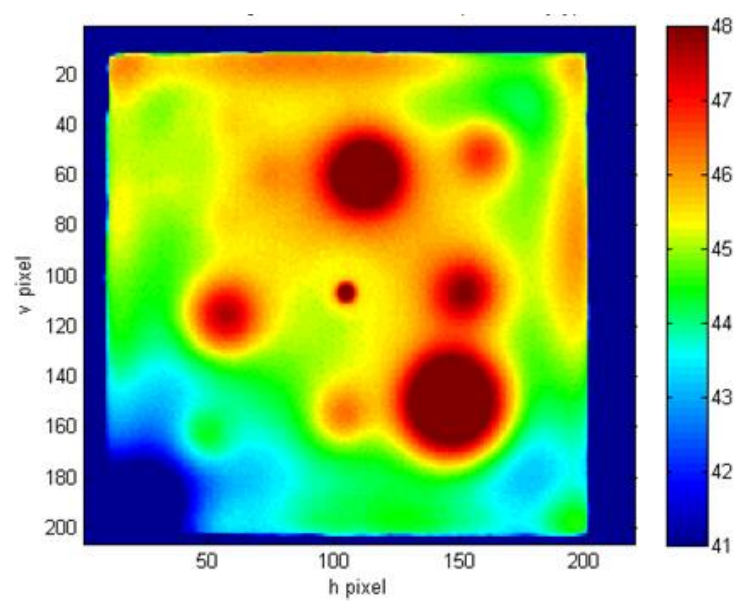

(a)

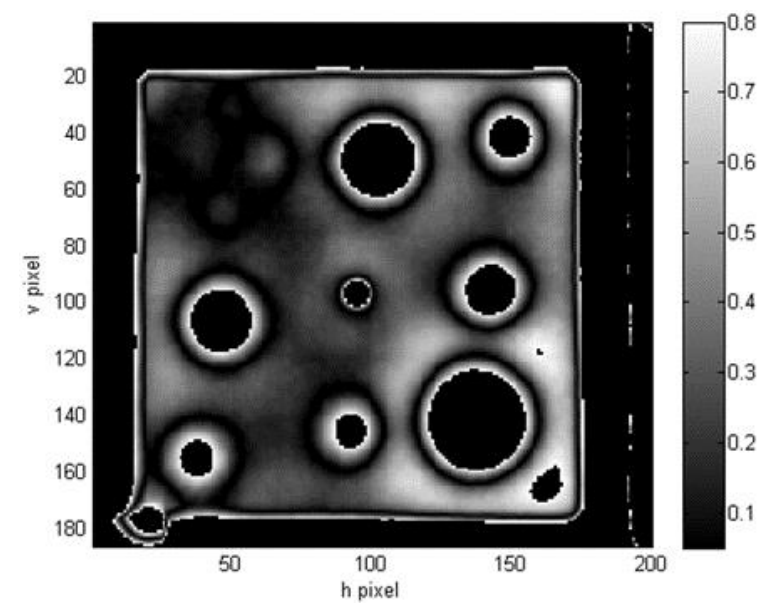

(b)

Figure 13. (a) Example of comparison between raw thermal map and (b) contrast map of CFRP Plate I/Side B.

Despite the heating not ideal, the contrasts map allows identification even the smallest defects of $5 \mathrm{~mm}$ diameter in a single specimen map (top left). The proposed contrast allows better evaluation of internal defects and is physically explained by the fact the thermal properties of defects are different from those of the surrounding material.

Contrast mapping has been optimized in order to highlight the most reliable boundary for defects of various types in carbon fiber plates, significantly reducing the noise effects and erroneous defective indications.

The greater depth of defects in the Plate I/Side A (4.9 mm of depth, in Figure 14a) causes difficulty of plate inspection and therefore we use longest heating times (Table 4). In the contrast map of Plate II/Side A (Figure 15b), four small defects of $5 \mathrm{~mm}$ diameter are clearly distinguished. Since, higher heating times do not allow smaller and deep defects detection; therefore, higher defect 
depth remain the main inspection limit and it was not possible to identify defects with less than $15 \mathrm{~mm}$ diameter (denominated D2, D4, D5, and D7 in Table 1) in Figure 14b, consequently the method allows to better distinguish all defects, but the physical limit of higher depth remains and small defects are still not visible. From CFRP Plate II acquisitions, the heating time of $15 \mathrm{~s}$ allows us to detect more clearly the greatest number of defects.

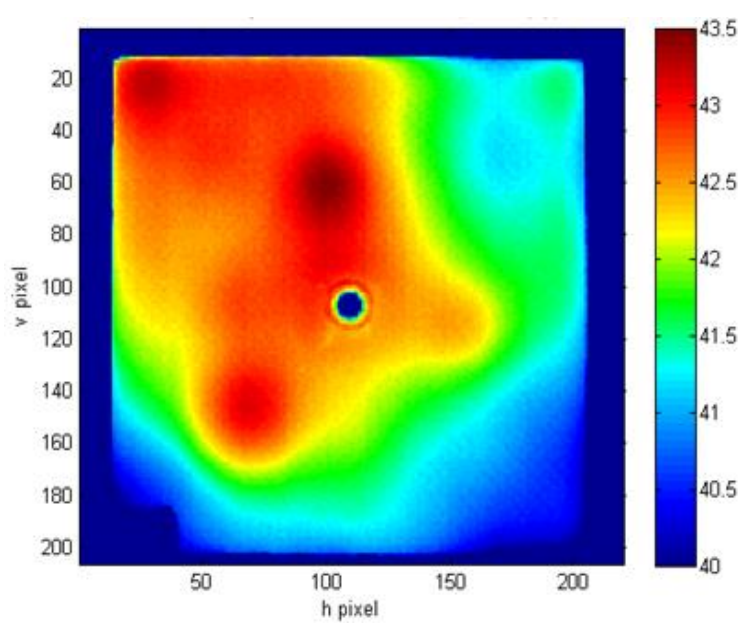

(a)

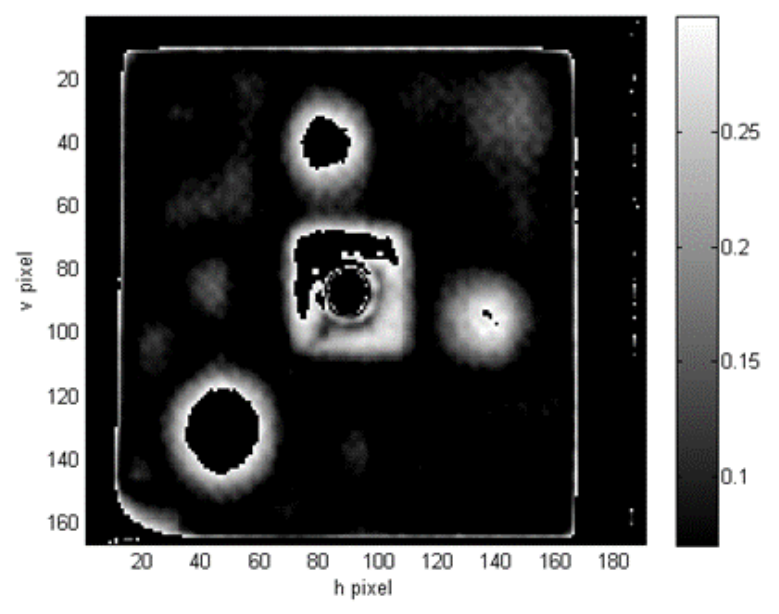

(b)

Figure 14. Comparison between raw thermal map (a) and (b) contrast Image of CFRP Plate I on Side A obtained after 39.4 cooling seconds after heating pulse of $30 \mathrm{~s}$.

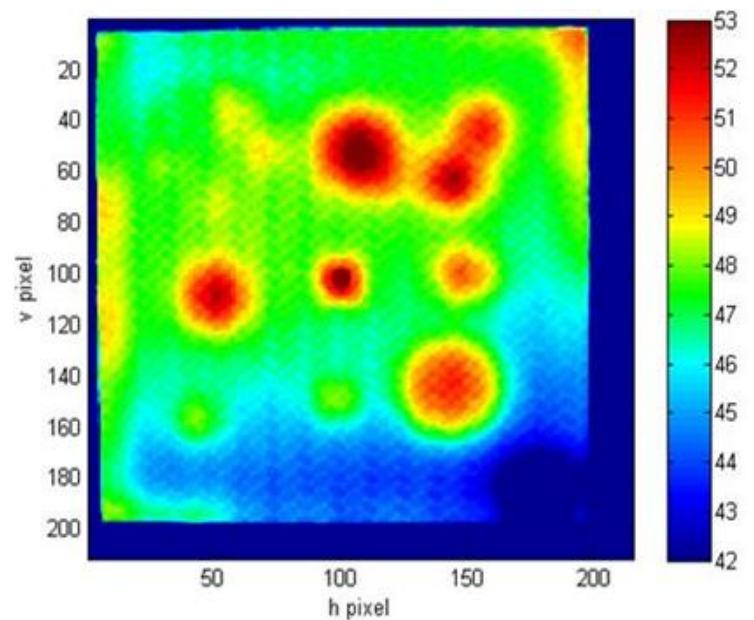

(a)

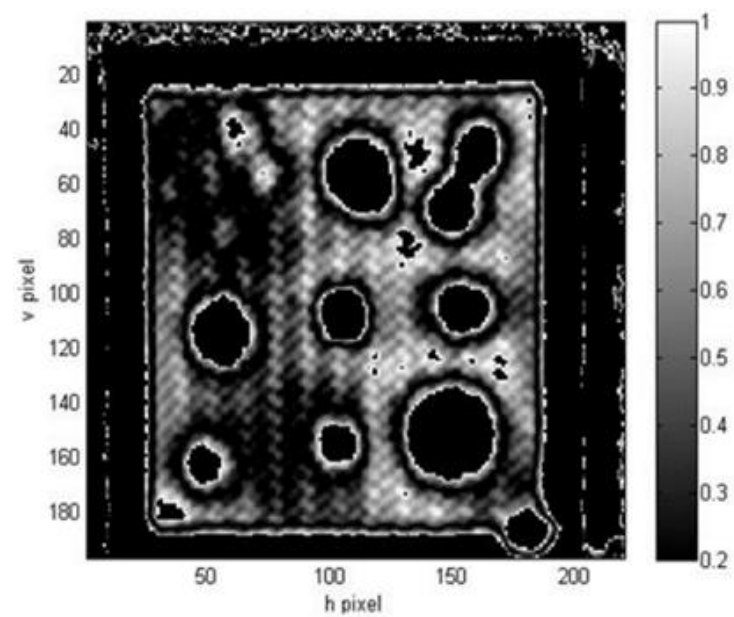

(b)

Figure 15. Comparison between raw thermal map (a) and contrast image (b) of CFRP Plate II on Side A obtained after 5 cooling seconds after heating pulse of $15 \mathrm{~s}$.

\section{Defect Mapping on Real Component and Results Discussion}

The authors performed ultrasonic inspections for a preliminary evaluation of damaged areas around central cut, caused by compression load test up to failure of real component; Figure 16 shows an example of ultrasonic phased array result with A-scan and S-scan measured in intact zone on the stringered skin. In the A-scan, signal amplitudes of contact echo and back-wall echo are clearly distinguishable in a single section slide, selected in the S-scan on the right; the amplitude peaks are steep and well positioned, showing good effect of wedge to eliminate sound pulse Fresnel disturbed zone at initial interface. Finally, in the s-scan is showed a third reflection in red, below the back-wall skin echo, representing the successive glued stringer echo of the caps. 


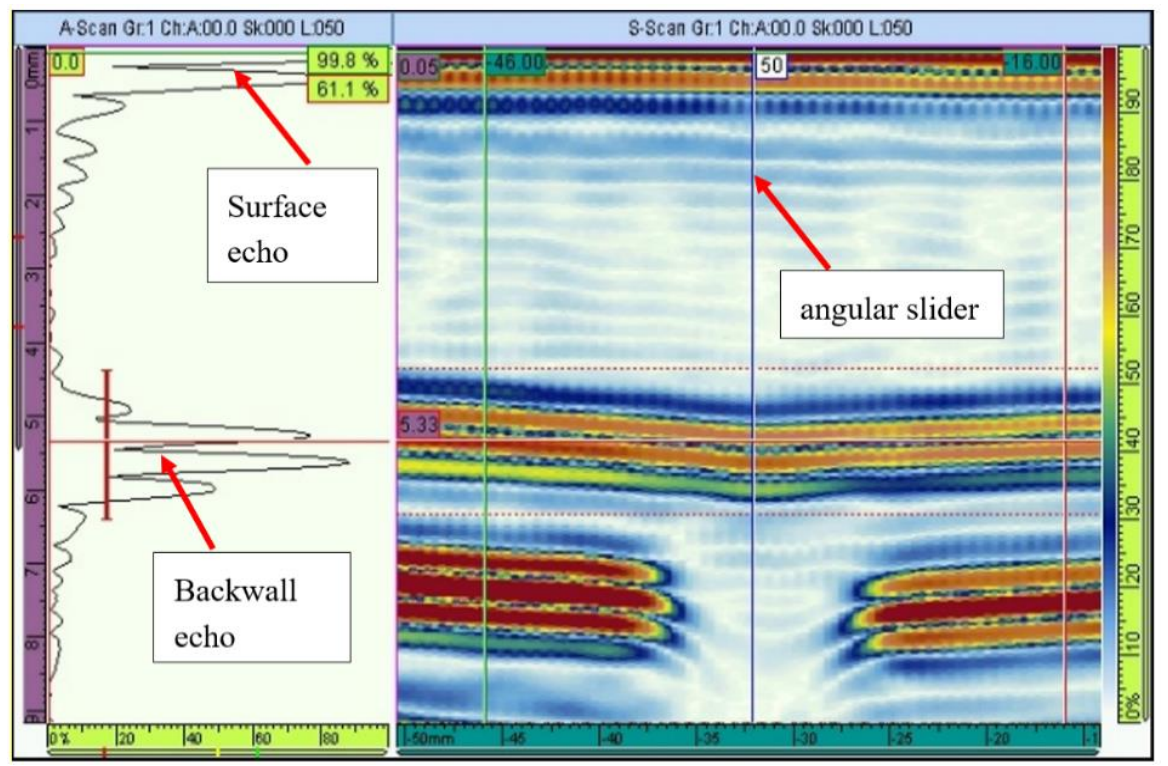

Figure 16. A-scan (left) and S-scan (right) of non-damaged zone around impact simulation cut.

For defect presence and size evaluation, a whole C-scan mapping of the damaged area is conducted in the functional direction along the simulated impact, where in Figure 17 are clearly highlighted the delamination distribution and their boundaries. The C-scan depth limits of UT inspections are chosen between 0.79 and $5.41 \mathrm{~mm}$ to analyze only the internal skin and not the skin/stringer interface below it.

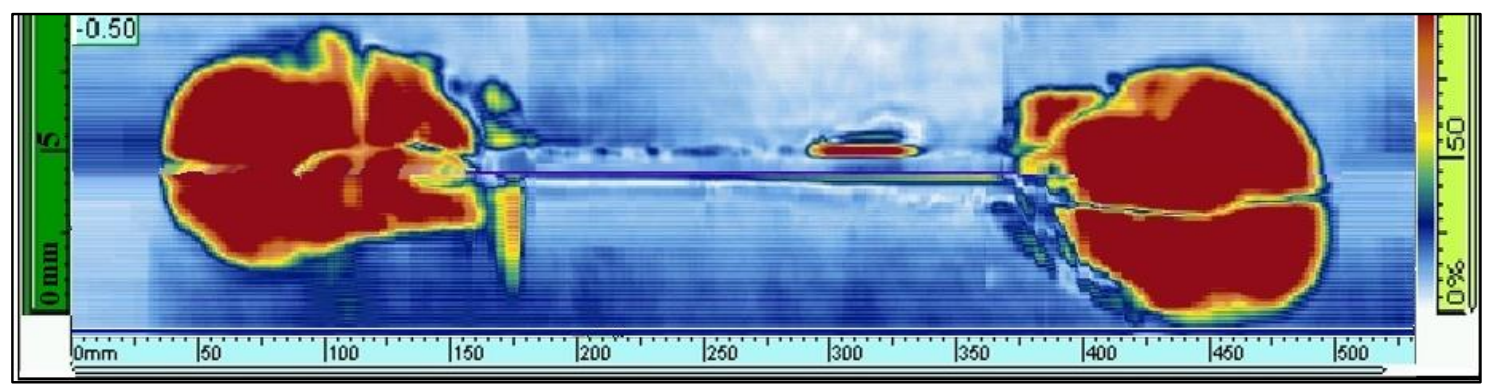

Figure 17. C-scan inspection over the multi-stringer component's surface on damaged zone along the artificial cut and an example of A-scan and S-scan on right side delamination.

In Figure 18, two ultrasonic local scans of damaged zone are representative of the widespread asymmetrical delaminations around the cut extremities, due to compression load testing. In the figures' s-scans, a linear $0^{\circ} \mathrm{S}$-scan direction normal to inspected skin surface is presented with a $38 \mathrm{~mm}$ horizontal axis width, corresponding to probe array length; evident multiple delamination echoes between several composite layers are displayed in both figures in the red zones of s-scans below the surface at depth in the range 2-3 mm, whose extension in progressively expanding more than $30 \mathrm{~mm}$ in width in different way at right- or left-side damage level is particularly elevate and back-wall/stringer signal disappear below the delaminated zone.

These UT results are compared with the thermographic analysis, using the specific setup and the experimental tests previously described. Thermal acquisitions are described in Table 5, with heating time of $3 \mathrm{~s}$ and $10 \mathrm{~s}$, and data are processed for contrast mapping, as shown in Figure 19a,b respectively. Thermographic inspections result shows delaminations clearly visible, but in this case, the local contrast map seems to slightly underestimate the defect extension with respect to UT C-scan results. This could be due to better calibration needs for the used algorithm on larger specimen sizes 
and geometry of target surface to inspect; in addition, the contrast map presents some differences than UT results as being referred primarily more realistic defect features in case of large delaminations. The authors, in fact, assume that the outer edges of the delaminations are extremely thin and in contact with each other, giving rise to occasional thermal continuity also in the damage area and this explains the difference from the thermographic point of view. For artificial defects this problem is absent and the enhanced contrast mapping procedure is optimized for the latter case.

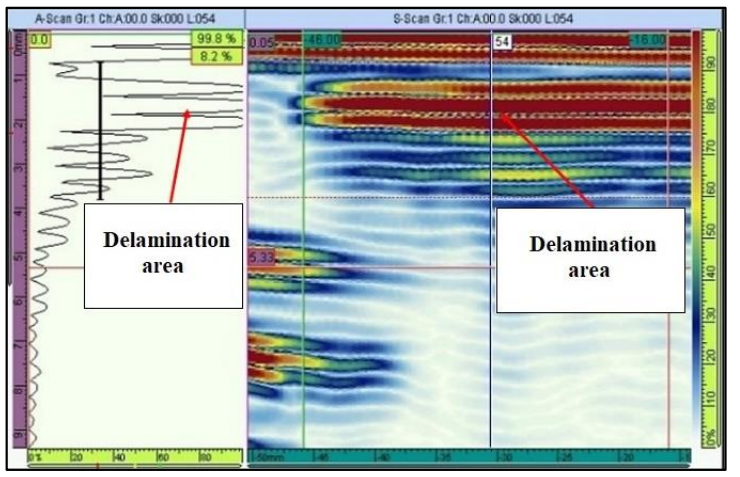

(a)

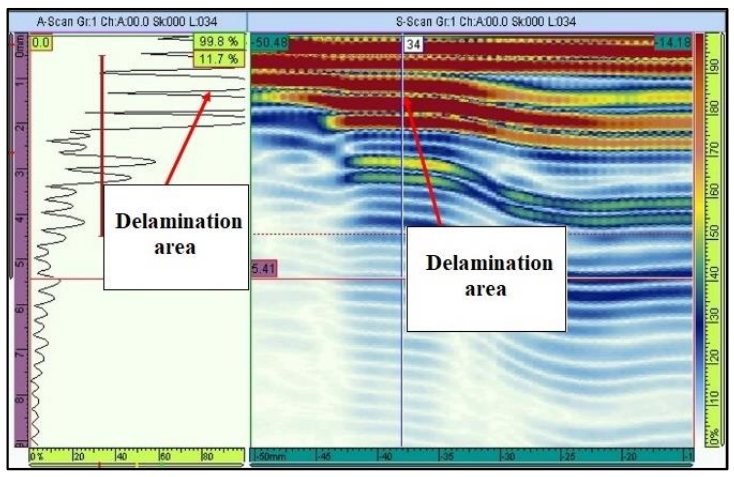

(b)

Figure 18. A-scan and S-scan of two damaged zones on the left side (a) and the right side (b) of impact simulation cut of multi-stringer component.

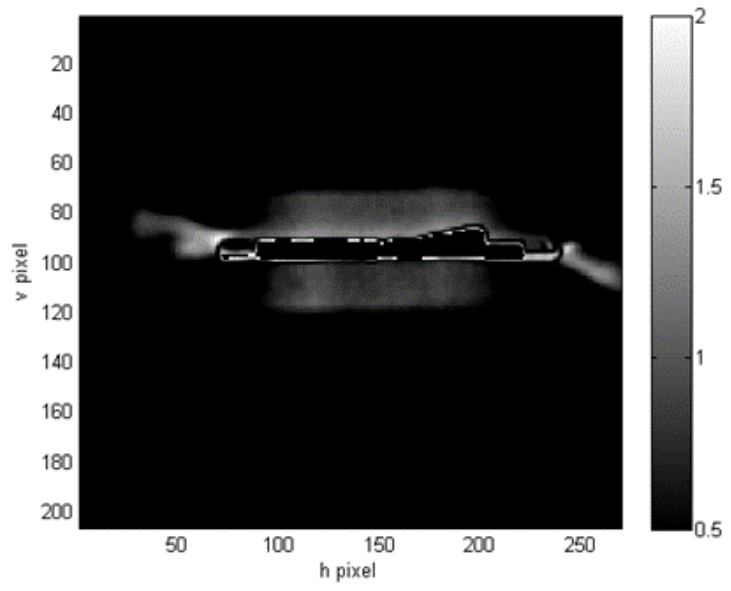

(a)

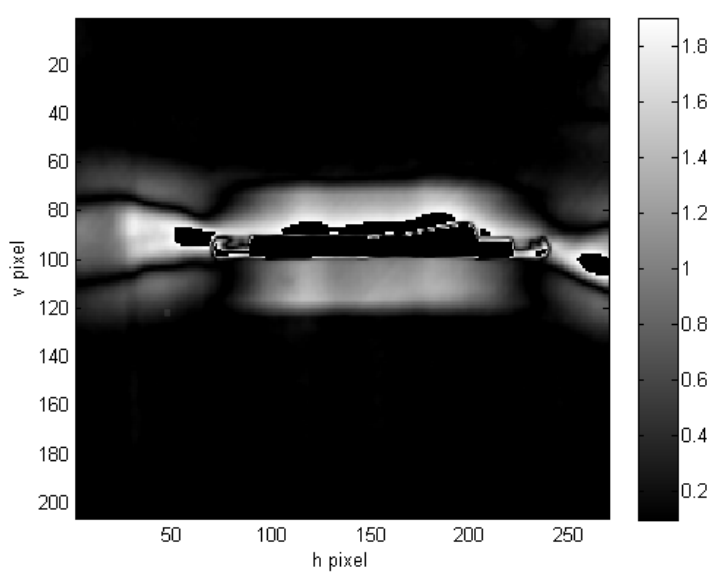

(b)

Figure 19. Contrast map of multi-stringer component using heating pulse of $3 \mathrm{~s} \mathrm{(a)} \mathrm{and} 10 \mathrm{~s} \mathrm{(b)}$.

The damage dimensions on left side of artificial impact simulation defect are estimated around an area of $112.5 \times 50 \mathrm{~mm}$ with the UT C-scan map; from raw temperature maps in Figure 6a and converting dimensions from pixels to millimeters, the delamination size is roughly in an area of $78 \times 38.5 \mathrm{~mm}$ and in alternative way equal to an area of $65.26 \times 20 \mathrm{~mm}$ as measured from Figure 20, achieved with the contrast elaboration map; in both cases, it seems the internal delamination is less extended and the UT inspections may overestimate the defect size. Furthermore, the new image processing method, based on a correlation between local temperatures, is observed to present disturbances when computed on the edges of the observed surface (the impact notch in the case of real component) due to the thermal gradients between the component and the environment around it, since the elaboration windows in a given point to be inspected will interfere with temperatures outside the inspected part. 


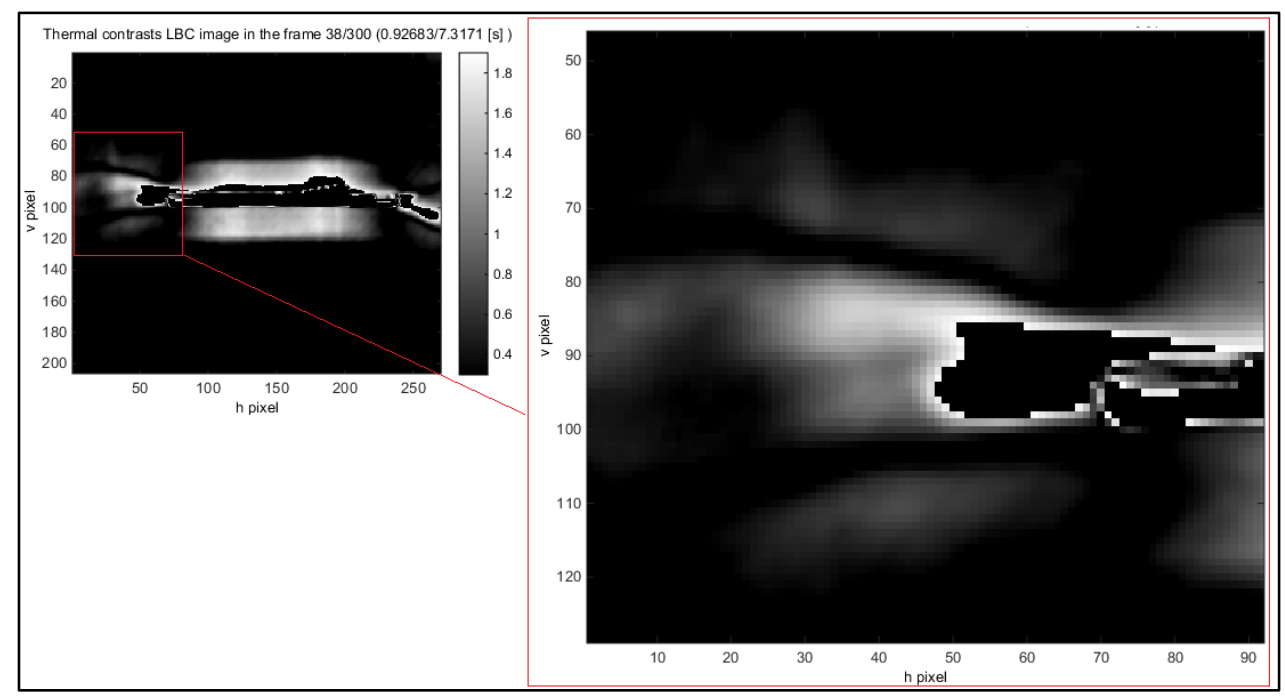

Figure 20. Contrast map of multi-stringer component using heating pulse of $7 \mathrm{~s}$.

Real delamination begins at the edges of the notch, which does not appear in real scale in the thermal map or contrast map due to the nature of the defect itself. Moreover, cause to larger size of the investigated component, the thermal resolution displayed in Figure 20 is much lower than resolution adopted for Plate I and Plate II specimens, giving rise to some differences originated by the contrast algorithm determination.

Future works may employ this new computation procedure on other NDT thermographic techniques, as examples the lock-in method or PPT, on different defect type, in order to certify the benefits of new contrast mapping.

\section{Conclusions}

The contrast maps allow highlighting all the defects displayed in the corresponding thermal maps; the larger defects' diameters are more noticeable than others, either on Side A or Side B of specimens. The depth at which the defects are located determines the thermographic visibility of the smaller ones and obviously, the defects observed are more easily identifiable and are greater in number if using the contrast in elaborated maps than those detected in classic way.

The inspection on real multi-stringer CFRP part shows satisfactory results either with the proposed thermographic contrast processing method, either with ultrasonic measurements, by means of modern phased array probe, distinguishing clearly and in accordance internal delamination in terms of extension and location.

The new contrast pattern allows to better visualize the defects edges, with a dependency on the depth and thickness of defect itself, but there are limitations; in fact, the definition of the image and the optical focus depends on thermal camera choice and operator set-up for the acquisitions and geometrical characteristics of the observed component.

Author Contributions: Supervision, V.D.; Methodology, F.W.P.; Data Curation, A.P.; Formal Analysis, A.P.; Investigation, A.S.

Funding: This research received no external funding.

Conflicts of Interest: The authors declare no conflict of interest.

\section{References}

1. Gholizadeh, S. A Review of Nondestructive Testing Methods of Composite Materials. Procedia Struct. Integr. 2016, 1, 50-57. [CrossRef] 
2. Usamentiaga, R.; Venegas, P.; Guerediaga, J.; Vega, L.; Molleda, J.; Bulnes, F.G. Infrared Thermography for Temperature Measurement and Nondestructive Testing. Sensors 2014, 14, 12305-12348. [CrossRef]

3. Galietti, U.; D'Accardi, E.; Palumbo, D.; Tamborrino, R. A Quantitative Comparison among Different Algorithms for Defects Detection on Aluminum with the Pulsed Thermography Technique. Metals 2018, 8, 859. [CrossRef]

4. Dattoma, V.; Giancane, S.; Panella, F.W. Fatigue damage in notched GFR composites with thermal and digital image measurements. In Proceedings of the ECCM15-15th European Conference on Composite Materials, Venice, Italy, 24-28 June 2012.

5. Danesi, S.; Salerno, A.; Wu, D.; Busse, G. Cooling down thermography: Principle and results for NDE. Proc. SPIE 1998, 3361, 266-274. [CrossRef]

6. Wang, Z.; Tian, G.; Meo, M.; Ciampa, F. Image processing based quantitative damage evaluation in composites with long pulse thermography. NDT E Int. 2018, 99, 93-104. [CrossRef]

7. Almond, D.P.; Angioni, S.L.; Pickering, S.G. Long pulse excitation thermographic nondestructive evaluation. NDT E Int. 2017, 87, 7-14. [CrossRef]

8. Usamentiaga, R.; García, D.F.; Molleda, J. Real-time adaptive method for noise filtering of a stream of thermographic line scans based on spatial overlapping and edge detection. J. Electron. Imaging 2008, 17. [CrossRef]

9. Sun, J. Analysis of data processing methods for pulsed thermal imaging characterization of delaminations. Quant. InfraRed Thermogr. J. 2013, 10, 9-25. [CrossRef]

10. Ibarra-Castanedo, C.; Bendada, A.; Maldague, X. Image and signal processing techniques in pulsed thermography. GESTS Int. Trans. Comput. Sci. Eng. 2005, 22, 89-100.

11. Balageas, D.L.; Chapuis, B.; Deban, G.; Passilly, F. Improvement of the detection of defects by pulse thermography thanks to the TSR approach in the case of a smart composite repair patch. Quant. InfraRed Thermogr. J. 2010, 7, 167-187. [CrossRef]

12. Rajic, N. Principal component thermography for flaw contrast enhancement and flaw depth characterization in composite structures. Compos. Struct. 2002, 58, 521-528. [CrossRef]

13. Bates, D.; Smith, G.; Lu, D.; Hewitt, J. Rapid thermal nondestructive testing of aircraft components. Compos. Part B Eng. 2000, 31, 175-185. [CrossRef]

14. Scarponi, C.; Briotti, G. Ultrasonic detection of delaminations on composite materials. J. Reinf. Plast. Compos. 1997, 16, 768-790. [CrossRef]

15. Jeong, H. Effect of void on the mechanical strength and ultrasonic attenuation of laminated composites. J. Compos. Mater. 1997, 31, 277-292. [CrossRef]

16. Kaczmarek, H. Ultrasonic detection of damage in CFRPs. J. Compos. Mater. 1995, 29, 59-95. [CrossRef]

17. Scarponi, C.; Briotti, G. Ultrasonic technique for the evaluation of delaminations on CFRP, GFRP, KFRP composite materials. Compos. Part B Eng. 2000, 31, 237-243. [CrossRef]

18. Dattoma, V.; Carofalo, A.P.; Palano, F.; Panella, F.W. ND Testing Advances on CFRP with Ultrasonic and Thermal Techniques. In Proceedings of the ECCM16-16th European Conference on Composite Materials, Seville, Spain, 22-26 June 2014. scopus Code 109290.

19. Giorleo, G.; Meola, C. Comparison between pulsed and modulated thermography in glass-epoxy laminates. NDT E Int. 2002, 35, 287-292. [CrossRef]

20. Dattoma, V.; Nobile, R.; Panella, F.W.; Saponaro, A. NDT Thermographic Techniques on CFRP Structural Components for Aeronautical Application. Procedia Struct. Integr. 2018, 8, 452-461. [CrossRef]

21. Ruiju, H.; Schmerr, L.W. Characterization of the system functions of ultrasonic linear phased array inspection systems. Ultrasonics 2009, 49, 219-225. [CrossRef]

22. Xiao, K.; Qiang, W.; Dong, H. Post Signal Processing of Ultrasonic Phased Array Inspection Data for Nondestructive Testing. Procedia Eng. 2012, 43, 419-424. [CrossRef]

23. Dattoma, V.; Nobile, R.; Panella, F.W.; Pirinu, A.; Saponaro, A. Optimization and comparison of ultrasonic techniques for NDT control of composite material elements. Procedia Struct. Integr. 2018, 12, 9-18. [CrossRef]

24. Susa, M.; Maldague, X.; Boras, I. Improved Method for Absolute Thermal Contrast Evaluation Using Source Distribution Image (SDI). Infrared Phys. Technol. 2010, 53, 197-203. [CrossRef]

(C) 2019 by the authors. Licensee MDPI, Basel, Switzerland. This article is an open access article distributed under the terms and conditions of the Creative Commons Attribution (CC BY) license (http:/ / creativecommons.org/licenses/by/4.0/). 